\title{
$O$ ato de cuidar: vivências e percepções de uma redutora de danos
}

\author{
Act of caring: experiences and perceptions of a harm reducer \\ Ana Carolina Oliveira Costa1 \\ DOI: $10.1590 / 0103-1104201912224$
}

RESUMO O presente texto expõe a experiência da relação de cuidado que uma redutora de danos estabeleceu em seu cotidiano profissional enquanto fazia parte do Programa de Redução de Danos do Distrito Federal (PRD-DF). Tem como objetivo compartilhar percepções e vivências do ato de cuidar com pessoas que faziam uso de drogas e se encontravam em situação de rua. Para isso, o relato de experiência foi utilizado como método. Muitos dos encontros entre redutora de danos e pessoas que faziam uso de drogas resultaram em um espaço de reciprocidades pautado em interações, diálogos e cuidados, o que levou a uma ressignificação do ato de cuidar como elemento que questiona o modo reducionista e tecnicista de relação com o outro. Buscar um encontro sujeito-sujeito e adotar uma perspectiva de cuidado que envolva o trabalho vivo em ato é um grande desafio quando se está inserido em uma lógica tão individualista dos desejos, afetos e das relações. Essas reflexões fortalecem ainda mais a ideia de construção de um ato de cuidar que seja mais humano e que preze pela multiplicidade dos sujeitos.

PALAVRAS-CHAVE Empatia. Redução do dano. Usuários de drogas.

ABSTRACT This paper exposes an experience of caring relationship that a harm reducer established in her professional life as a member of the Harm Reduction Program of the Federal District (PRD$D F)$. It aims to share perceptions and experiences of caring for people who use drugs and were in a homeless situation. For this, the experience report was used as a method. Many of the encounters between the harm reducer and people who used drugs resulted in a space of reciprocity based on interactions, dialogues and care, which led to a resignification of caring as an element that questions the reductionist and technicist mode of relationship with others. Seeking a subject-subject encounter and adopting a care perspective that involves living work in action is a great challenge when one is inserted in such an individualistic logic of desires, affections and relationships. These reflections further strengthen the idea of building an act of caring that is more human and that values the multiplicity of subjects.

KEYWORDS Empathy. Harm reduction. Drug users.

1 Secretaria de Saúde do Distrito Federal - Brasília (DF), Brasil.

ana.oliveiracosta@hotmail. com 


\section{Introdução}

O cuidar representa uma atitude, antes mesmo de ser revelado como uma ação ou um ato. De forma mais abrangente, inclui em seu conceito o desvelo, a atenção, a responsabilização e o envolvimento com o outro ${ }^{1}$. Holanda ${ }^{\mathbf{2}}$ coloca que falar de cuidado passa necessariamente pela consideração do outro, pela apreensão dos seus modos de produção de subjetividade, modos de sentir, de vivenciar as necessidades, enfim, pela apreensão de sua diversidade.

Contudo, essas relações inserem-se em aberta contradição com a lógica que compõe o cenário contemporâneo. A desvalorização da alteridade e a clara concepção individualista tornam-se dominantes, e essa relação com o outro pode ser expressa tendo a desumanização como produto. Esse fenômeno se reflete, também, nas relações de cuidado, fazendo com que o ato de cuidar se apresente muitas vezes como uma técnica em que se sobressai o seu valor comercial, uma técnica do tipo 'linha de produção'3. Esse modo taylorista de cuidado coloca-se na incumbência da administração de pessoas como se fossem 'coisas' ou recursos despojados de vontade e autonomia ${ }^{4}$.

Nesse contexto, em confronto com o processo de desumanização, a proposta da Redução de Danos (RD) pode ser citada como um dispositivo que provoca uma discussão e questiona a lógica mecanicista e biologicista de relação com o outro. Como tal, ela se estrutura na oferta de serviços mais acessíveis, a partir de uma ótica desburocratizada, aberta e flexível. São ações que se configuram na minimização de riscos e danos de natureza biológica, psicossocial e econômica, provocados de forma direta ou indireta pelo uso e abuso de drogas, sem necessariamente requererem a abstinência do consumo de tais substâncias ${ }^{5}$. Cabe ressaltar que, quando a interrupção do uso de drogas não for desejada ou possível, outros agravos de saúde podem ser evitados ${ }^{6}$.
Conte nos traz que as estratégias de $\mathrm{RD}$ originaram-se com o Relatório de Rolleston, em 1926, no qual ficava estabelecido que médicos poderiam prescrever opiáceos para adictos dessa substância. Já nos anos 1980, com o advento da epidemia de Vírus da Imunodeficiência Humana/Síndrome da Imunodeficiência Adquirida (HIV/Aids), outras ações de RD foram desenvolvidas com o objetivo de prevenção à saúde ${ }^{7}$. No Brasil, a RD também se materializa em ações e compõe alguns pontos da política pública de saúde. No entanto, mesmo após seu reconhecimento enquanto princípio e uma forma de cuidado com o outro, é possível perceber obstáculos que lentificam sua consolidação. Como exemplo, pode-se citar a aprovação do Decreto Presidencial no 9.761, de 11 de abril de 2019, o qual dispõe a abstinência como o princípio norteador do cuidado de pessoas que fazem uso de drogas ${ }^{8}$. Apesar dos esforços governamentais em modificar mais enfaticamente o foco de atuação, a RD ainda se faz presente na política pública. Um dos exemplos é colocado na Portaria $\mathrm{n}^{0} 3.088$, de 2011, na qual a RD aparece como uma das diretrizes para a instauração da Rede de Atenção Psicossocial (Raps) ${ }^{9}$. Ela também compõe a política de prevenção combinada ao HIV/Aids, posicionando-se como uma das fatias da mandala da prevenção combinada e como uma ação transversal10. Dessa maneira, observa-se que as ações de RD seguem como uma abordagem que questiona o modelo proibicionista/punitivo e propõe uma nova ética de cuidado.

Nessa perspectiva, o que se percebe é que a RD permite um movimento que coloca os participantes em outra forma de relação com o social e que se posiciona como ponte entre o sujeito e o laço social do qual está apartado ${ }^{7}$. A partir da troca de informações e materiais, os usuários, ao sentirem-se investidos, passaram, também, a trocar afetos, olhares, pedidos, entre outros. A extensão dessas trocas possibilita, muitas vezes, a entrada de um terceiro na relação dual que 
o usuário estabelece com as drogas. Nesse ponto, o redutor de danos se faz presente e há um maior cuidado com o sujeito ${ }^{7}$.

O ser humano tem necessidade das tecnologias das relações, aquelas que têm produção de comunicação, de acolhimento, produção de vínculos e autonomização, as denominadas por Mehry" como 'tecnologias leves' ou tecnologias do cuidado, por assim dizer. Estas têm em si a produção de reciprocidade e de interação, que são indispensáveis ao ato de cuidar. Assim, o processo de interação funda-se no encontro com o outro. Contudo, esse encontro não é aquele calcado na indiferença, mas, sim, em uma relação na qual os sujeitos afetam e são afetados mutuamente, aprendem e trocam experiências.

Tendo por base essa relação de cuidado estabelecida no encontro entre o profissional e o usuário de drogas, o presente trabalho tem como objetivo compartilhar histórias marcantes da autora como redutora de danos.

\section{Metodologia}

Trata-se de um estudo qualitativo que se utilizou do relato de experiência. De acordo com Simon, a sistematização da experiência se faz necessária, pois, a partir dela, há um compartilhamento com outros aprendizados, além da socialização de elementos, crenças e valores de fenômenos inéditos e irrepetíveis ${ }^{\mathbf{1 2}}$. O processo de reconstrução da experiência produz um novo conhecimento, converte a vivência em objeto de interpretação teórica e de estudo e recupera de maneira ordenada os fenômenos.

O relato foi realizado a partir da experiência de dois anos da pesquisadora como redutora de danos no extinto Programa de Redução de Danos do Distrito Federal (PRD-DF) e se dividiu em dois momentos: o primeiro se destinou à descrição das informações referentes aos acontecimentos em campo e aos encontros com os sujeitos; já no segundo momento, houve o entrelaçamento desse conhecimento com as fundamentações teóricas.

\section{Resultados e discussões}

\section{Uma experiência, um relato}

O PRD foi um serviço que vigorou no DF por dezesseis anos. Ele fazia parte da gerência de DST/Aids e hepatites virais e encontra-se inativo atualmente. Não quer dizer, porém, que não existam ações de RD no DF. Vale dizer que outros grupos continuam a trabalhar prioritariamente com tais ações. Contudo, compete a este estudo a apresentação de registros de vivências que se passaram no período em que trabalhei como redutora de danos nesse mesmo programa. O PRD não possuía um local próprio usado para atender alguém especificamente, nem um consultório com mesas e cadeiras dispostas nos moldes tradicionais. Seu local privilegiado de trabalho era a rua. Sempre ouvi dos outros companheiros de trabalho que um redutor de danos traçava sua construção, primeiramente, em campo, ou seja, no local em que o sujeito que faz uso de droga estivesse presente. Meu percurso não foi diferente. Também entendi o que era RD nos momentos em que saía para o campo. Juntamente com outros redutores, seguia o percurso de algumas regiões previamente mapeadas.

Nos primeiros dias de trabalho, passei por um treinamento. Recebi uma mochila com diversos insumos - materiais utilizados pelos redutores de danos, como folders, piteiras, cachimbos, preservativos (masculinos e femininos), gel lubrificante, kits, entre outros - e alguns direcionamentos sobre como estar em campo. Nada mais. Nenhum protocolo, nenhum manual a seguir. As orientações para o trabalho perpassavam princípios da $\mathrm{RD}$, como pragmatismo, tolerância, diversidade, acrescidos do respeito e do cuidado ao outro.

Apesar de todo redutor de danos caminhar com seus materiais de trabalho, eu sentia que o recurso mais importante atravessava o campo do simbolismo. Conseguia identificar a 'presença' como um forte elemento e me identificava, também, enquanto um sujeito-recurso. 
Os encontros eram sempre com o desconhecido. Mesmo seguindo um ritual de ida semanal a campo, nos mesmos dias e horários, e, por tantas vezes, aproximando-nos dos mesmos grupos, uma palavra, um gesto e o contexto faziam-se novidades. O meu olhar, aos poucos, era treinado a estar atento ao ambiente, às relações que ali se pautavam, aos códigos locais e, principalmente, ao que o sujeito comunicava sem, muitas vezes, o auxílio das palavras.

Das tantas pessoas encontradas, em pelo menos dois anos de trabalho, observei que a maioria era composta por homens adultos. Muitos estavam sozinhos, tendo como companhia somente os seus carrinhos, onde guardavam suas roupas, documentos e instrumentos de trabalho. Para eles, os carrinhos configuravam um dispositivo importante, cheio de significados, e compunham o cenário de sua existência. As crianças, por sua vez, sempre apareciam rapidamente e pareciam desconfiadas, olhando para o chão, como se estivessem à procura de algo. Eu não conseguia apreender seus olhares, e o contato com elas, muitas vezes, durava não mais que poucos minutos. Os outros atores, compostos também por mulheres e pessoas idosas, trabalhavam como vigias de carro ou lavando o chão desse ou daquele comércio.

O campo, com seus horários definidos, atores diversos e relações, transformava-se ao longo das horas. Pude experimentar sair às sete horas da manhã, em meio aos ventos gelados das primeiras horas do dia, bem como tive a oportunidade de trabalhar nas tardes e noites da cidade. Cada período revelava uma dinâmica própria à qual eu tinha que me adaptar e entender.

Pude presenciar uma série de falas ou pequenos gestos carregados de simbolismo, como, por exemplo, o olhar penetrante de uma idosa de quem me aproximei. Ela tinha seu rosto e corpo cobertos por um pano. Ao ser interpelada, rapidamente tirou o pano de sua face, mas fez questão de esconder um cachimbo. Disse que não queria que eu o avistasse. Então, agachei-me para ver seus olhos e fazê-la entender que, naquele momento, o cachimbo não era o meu foco. Ela olhou-me profundamente e com intensidade, mostrou o cachimbo, contou brevemente sua história, e eu a acolhi. Havia certa vergonha por fazer uso de drogas, admitia ela. Para não olhar para o rosto dos outros, escondia o próprio.

Em outra região, havia um bueiro no qual algumas pessoas passavam a maior parte do dia. Elas dispunham do espaço para uso de substâncias e, muitas vezes, para dormir. Homens com os quais eu interagia, quase que com o rosto dentro do local, conversavam comigo e pediam os insumos.

Houve, também, um dia em que encontrei uma criança tão falante que, com um sorriso no canto da boca, mostrava-me seu paninho e um vidro com álcool, guardados dentro de uma caixinha decorada. Dizia que usava aqueles materiais para limpar o machucado que tinha na perna e que precisava cuidar de seu corpo. Falava e demonstrava, à sua maneira, sobre os saberes aprendidos em sua caminhada, e ia ficando claro que, de alguma maneira, esses saberes conversavam com aqueles pensados pela $\mathrm{RD}$.

Estar perto, pegar a mão, agachar, olhar nos olhos, interagir, trocar experiências, passar informações de saúde, falar sobre assuntos do cotidiano, da rotina dos sujeitos, entre tantos outros elementos, apresentavam-se para mim como modos de cuidado que dialogavam com a realidade daquelas pessoas. Eram modos de cuidado pelos quais se pretendia pensar o sujeito e não somente o uso de substâncias.

\section{$O$ vínculo, o cuidado e o encontro}

Por vezes, refleti sobre as relações que os redutores de danos estabeleciam com as pessoas que consumiam drogas. $\mathrm{O}$ que representou essa aproximação? O que representou e o que representa ir a locais onde muitos não vão, marcados pela escassez e pela violência (simbólica e concreta)?

Esses são cenários onde as relações também são construídas. São locais em que, ao mesmo tempo que são reveladas as vulnerabilidades de 
atenção e as lacunas nas políticas públicas direcionadas a essas populações (que se caracterizam pela presença de pessoas em situação de rua, em uso de drogas, profissionais do sexo, entre outros), também ficam visíveis as formas de resistência e as diversas maneiras de sociabilidade. Presenciei relações de cuidado se firmarem, grupos inteiros que se ajudavam para poderem sobreviver na rua e, ainda, os diálogos que se utilizavam de saberes populares e tradicionais para a resolução de questões de saúde. Deparei-me com pessoas que acolhiam cachorros, com a divisão de marmitas entre comerciantes e pessoas que viviam na rua. Certa vez, um grupo me contou sobre a dinâmica de suas noites na rua. Segundo eles, revezavam-se para dormir, a fim de se protegerem. Por entre os becos e 'mocós', como diziam, muita relação de descuido também acontecia, como as brigas e repressões entre policiais e pessoas que faziam uso de drogas.

Nessa aproximação com os sujeitos, percebia que o redutor de danos oferecia muito mais que um insumo ou um material. Oferecia a possibilidade de um cuidado diferenciado, que dizia respeito ao acolhimento do sofrer e do incômodo do outro, bem como de sua alegria. Configurava-se em um respeito ao modo de a pessoa ser e estar no mundo.

Por vezes, quando chegávamos a campo, alguns sujeitos nos seguiam. Não raro, faziam boa parte do percurso do nosso lado. Ora conversando, ora em silêncio. Percebia que estavam ao nosso lado em busca de algo a mais. Um algo que não era um insumo, mas que se configurava em 'estar-com'.

Vejo a relação com o sujeito marcada pela liberdade. A pessoa era livre inclusive para não aceitar, naquele momento, os cuidados e aproximações oferecidos pelos redutores de danos. A conduta era sempre a de respeitar a distância trazida pelo sujeito, de lembrar que estaríamos ali toda a semana e, por fim, de mencionar a nossa disponibilidade para uma conversa, escuta ou silêncio.

\section{Discutindo com os autores}

Uma das características que mais chamaram atenção no cotidiano de trabalho da RD foi o 'mover-se'. Percebia que sempre estava andando pelas ruas e, nisso, observava. Por entre os caminhos, quando me deparava com alguém que fazia uso de drogas, percebia que o fato de ser redutora de danos tornava-se a primeira e, talvez, a principal forma de aproximação, que denominarei 'movimento do cuidado'.

Percebia que meu movimento em direção àquele sujeito resultava na interação com o universo do outro, provocando um espaço de trocas. É a partir desses encontros intersubjetivos que há a existência da possibilidade de que as pessoas sejam afetadas, "sendo coautoras das trajetórias umas das outras"13.

Segundo Luczinski e Ancona-Lopez ${ }^{13}$, a relação com o sujeito

não se dá a partir de um esquema mental prévio, mas implica em estar disponível para ele assim como se mostra no dado momento, deixando suspensas as preconcepções.

É assim, também, na fenomenologia. Esse campo do saber pensa as coisas do mundo como fenômenos, e, para entendê-los, precisa-se de uma redução fenomenológica, ou seja, da suspensão dos conhecimentos a priori para a compreensão genuína daquilo que se está mostrando. O meu trabalho como redutora ilustrou um pouco essa questão. No momento em que se dava o encontro com o sujeito, era preciso deixar os conhecimentos prévios em um outro lugar, para que o encontro com o outro e com o fenômeno ali posto fosse feito a partir de uma posição de não julgamento. $\mathrm{O}$ encontro genuíno e o acolhimento aconteciam a partir da disponibilidade de cada redutor em sua relação com o usuário ${ }^{2,14}$. Essa disponibilidade, por sua vez, significa estar aberta a tocar e a 'deixar-se' tocar pela presença da alteridade e, consequentemente, arcar com os efeitos desse impacto e dessa presença ${ }^{13,15}$. 
Estar no lugar de redutora de danos é vivenciar a presença como recurso. Percebi que, em um aperto de mão, um abraço, uma conversa sobre o cotidiano e, sobretudo, na escuta, oferta-se cuidado. Um cuidado leve, que não possui em si instrumentos rebuscados ou recursos demasiadamente tecnológicos; um cuidado que se esforça em não transformar o outro em um mero objeto e que não coloca seus protagonistas em uma relação verticalizada ${ }^{16}$. Nesse sentido, Bastos e Alberti ${ }^{17}$ colocam que a RD é subversiva, pois parte do princípio de que é preciso escutar os sujeitos, pois deles nada se sabe. É dessa escuta e da comunicação que se coloca em prática o almejado pela reforma psiquiátrica. A RD é subversiva, sobretudo porque questiona essa mesma reforma e "a dominação dos corpos pelo discurso moral/biológico"17(218).

Anéas e Ayres ${ }^{18(659)}$ lembram, ainda, que, "no voltar-se à presença do outro no cuidado [...], deve-se ter claramente quem é este outro". Esse sujeito que aparece para mim é alguém inserido em um contexto, que é dotado de subjetividades e desejos e que carrega consigo memórias e experiências ${ }^{\mathbf{1 8}}$. Dessa maneira, os autores ressaltam que

deve-se compreender e ter uma escuta deste outro como aquele que construiu e constrói uma história particular de existência, mas que não é separado do mundo que o rodeia em seus significados compartilhados ${ }^{18(659)}$.

Pensando nessa singularidade, Ribeiro ${ }^{6}$ traz que a RD considera a complexidade do fenômeno, as singularidades culturais e psicológicas dos sujeitos, ponderando todas as variáveis possíveis para o melhor encontro com o outro.

$\mathrm{O}$ ato de cuidar também fala de acolhimento e responsabilização, palavras que suscitam em mim a lembrança de uma moça que encontrei certa vez. Em meio a um comportamento agitado e passos rápidos, topou comigo. Perguntei se estava tudo bem e se ela precisava de alguma ajuda, e, antes mesmo de terminar, ela me abraçou, disse que sim e que precisava conversar. Naquele encontro, criou-se um espaço comunicacional no qual "houve a conversão ontológica do homem conjugado na voz impessoal para o homem em primeira pessoa"18(660). Ela falou sobre aquilo que a incomodava e de como isso impactava o seu estado emocional naquele momento. Ela era o foco, não o cachimbo que estava em sua mão.

Nessa perspectiva, naquele diálogo estabelecido com a moça, as palavras que povoaram esse espaço comunicacional constituíram-se como gesto inscrito no mundo e como uma ação. De acordo com Luczinski e AnconaLopez ${ }^{\mathbf{1 3 ( 7 9 )}}$, é por isso que a "palavra falante que resulta de um encontro verdadeiro atualiza o ser do homem e transforma-o", apontando diversas possibilidades de os sujeitos serem e estarem no mundo. Para isso, Conte enfatiza a importância de uma escuta e uma comunicação que não se resumam ao fenômeno das drogas e de intervenções que não estabeleçam ideais utópicos que desconsiderem a posição do sujeito no mundo e a posição que a droga ocupa na vida dele?

No dia a dia como redutora, escutei diversas histórias de vida. Histórias da rua, da dificuldade de se viver nela, do cotidiano sofrido e muitas lembranças. A escuta, dessa maneira, faz-se necessária e se torna recurso valioso. Segundo Heidegger, a escuta traz à luz o 'ser-com', pois sempre se escuta o outro e o mundo em uma reciprocidade. Para o Dansei, ela é muito significativa, já que ele nunca ouve somente barulhos. Tais barulhos sempre estarão mergulhados em um contexto com possibilidades significativas e serão interpretados ${ }^{18}$.

Deve-se entender que ali existe um ser dotado de subjetividade e desejos e ter a consciência de que qualquer inferência que se faça sobre aquele indivíduo poderá ser incomensurável14. É preciso percebê-lo na sua singularidade e na sua alteridade, em uma atitude de contemplação, e não de mera observação ${ }^{13}$. Deve haver concentração exclusiva na experiência a qual se presencia, para que haja 
uma apreensão mais profunda dos fenômenos presentes naquela cena de uso. Notei que em uma abordagem sem ideias preconcebidas e formulações a priori, o entendimento da realidade se dá de um modo mais sensível. É preciso buscar no fenômeno aquilo que ele fala, pois há sempre uma comunicação.

Falar do cuidado é dar conta da diversidade, e isso passa, necessariamente, pela consideração do outro ${ }^{2}$. No momento em que estive inserida no cenário da rua e me deparava com alguém portando diversos cachimbos de crack (algo que presenciei diversas vezes), e que se dispunha a contar sobre como eles haviam sido construídos, percebia que tinha à minha frente alguém disposto a uma interação, disposto a compartilhar comigo informações que tangem à sua existência. Sobre isso, Ayres apud Anéas e Ayres diz que

o cuidado se dá em um contínuo das relações [...] em todas as oportunidades que se faça possível entender aquilo que o outro traz em relação à sua existência'18(659).

A RD, dessa maneira, posiciona-se de forma a respeitar a existência do sujeito e a distância estabelecida por ele, para que limites pessoais não sejam ultrapassados nessa relação ${ }^{7}$.

Uma das cenas clássicas do trabalho da RD é a do profissional orientando a pessoa que faz uso de drogas sobre como esta poderia fazer um uso mais saudável da substância, o que era, de certa maneira, desconcertante para aqueles que nunca tiveram contato com a RD. Muitos achavam que isso dizia respeito a uma apologia, outros a uma permissividade sem limites. Eu percebia como uma outra ótica do cuidado. Conte ${ }^{7}$ enxerga essas ações como um auxílio ao sujeito no posicionamento do cuidado de si e da responsabilização por seus atos no mundo. Para a autora,

a aproximação dos redutores de danos com esta população vulnerável trabalha as condições de existência que permitirão ao sujeito demandar tratamento ou outras formas de auxílio, ou inclusão social7(31).
Sobre isso, Ribeiro 6 ressalta, ainda, que a $\mathrm{RD}$ percebe o usuário não como um sujeito fruto de sua tutela, mas, sim, como sujeito de direitos, que tem plena capacidade de protagonizar seu cuidado e se responsabilizar pelas modificações necessárias para a melhoria de sua própria vida.

Muitas vezes, a simples entrega de um material ou de um folheto explicativo iniciava um diálogo, corroborando o apontamento de Rui ${ }^{19}$ para a capacidade que esses insumos possuem de incitar uma relação entre os sujeitos presentes na cena.

Quando explicava qual era a serventia daquele tubinho de silicone chamado de piteira, percebia que, em muitos momentos, aquilo rendia conversas, fossem elas sobre o governo, sobre o porquê daquele insumo ou sobre a própria RD. Rui19 pontua que, por meio de um objeto concreto, há a criação de laços de afinidade, que, para os redutores de danos, são de fundamental importância, já que possibilitam que os usuários de drogas percebam e cuidem de seu próprio corpo. Cabe enfatizar que o acesso a informações diz respeito à ampliação dessas possibilidades de cuidado de si e das escolhas que se relacionem com o cotidiano de cada sujeito.

Entretanto, é necessária uma ponderação no que diz respeito a essa abordagem, para que não haja a reprodução do modelo biomédico, de um pensamento mecânico acerca do sujeito, de "um modelo cartesiano de homem e de mundo"18.

Buscar um encontro sujeito-sujeito e adotar uma perspectiva de cuidado que envolva o trabalho vivo em ato é um grande desafio quando se está inserido em uma lógica tão individualista dos desejos, dos afetos, das relações. Essas reflexões fortalecem ainda mais a ideia de construção de um ato de cuidar que seja mais humano, genuíno e cotidiano ${ }^{3}$.

\section{Considerações finais}

Esta construção certamente não tem a pretensão de ser uma obra finalizada, mas de socializar as vivências e os sentidos atribuídos por uma redutora de danos ao ato de cuidar, 
além de provocar uma reflexão acerca dessa temática. Nem mais, nem menos.

Nos encontros expostos, a escuta, a troca de saberes, o toque, a expressão de afeto e a conversa marcaram não só a construção de uma relação de cuidado que buscava ser mais autêntica, mas a possibilidade de uma relação pautada pela autonomia do sujeito e pela oferta de cidadania. Um movimento diferente daqueles inspirados na tutela, caridade ou vitimização do sujeito.

A RD assume a base para as intervenções e o olhar da pesquisadora e reforça o compromisso ético-político do contato com o outro. Tratase de pensar o sujeito em sua integralidade, fazendo valer um dos princípios do Sistema Único de Saúde, e de, sobretudo, perceber que sua existência está para além do uso de drogas.

A proposta aqui foi tão somente a de uma ressignificação do ato de cuidar, apontando a RD como peça fundamental para se entender o complexo fenômeno das drogas e como possibilidade de oferta de um tratamento mais dialógico com as reais necessidades dos sujeitos que fazem uso dessas substâncias.

\section{Colaboradores}

Costa ACO (0000-0002-6374-3915)* foi responsável pela concepção, planejamento, análise e interpretação dos dados, revisão crítica do conteúdo e aprovação da versão final do manuscrito.

\section{Referências}

1. Boff L. Saber cuidar: ética do humano-compaixão pela terra. Petrópolis: Vozes; 1999.

2. Holanda AF. Fenomenologia do "cuidado": reflexões para um olhar sobre o binômio saúde-doença. In: Peixoto AJ, Holanda AF, coordenadores. Fenomenologia do cuidado e do cuidar. Perspectivas multidisciplinares. Curitiba: Juruá; 2011. p. 67-83.

3. Plastino CA. A dimensão constitutiva do cuidar. In: Maia MS, organizador. Por uma ética do cuidado. Rio de Janeiro: Garamond; 2009.
4. Campos GWS. O anti-Taylor: Sobre a invenção de um método para co-governar instituições de saúde produzindo liberdade e compromisso. Cad. Saúde Pública. 1998; 14(4):863-870.

5. Pereira VFS. Um estudo da experiência de implementação do programa de redução de danos ao uso de drogas no Distrito Federal [dissertação]. Rio de Janeiro: Escola Nacional de Saúde Pública Sergio Arouca, Fundação Oswaldo Cruz; 2007.

6.

Ribeiro MM. Drogas e redução de danos: os direitos das pessoas que usam drogas. São Paulo: Saraiva; 2013.
*Orcid (Open Researcher and Contributor ID). 
7. Conte M. Psicanálise e redução de danos: articulações possíveis. Rev. Assoc. Psicanal. Porto Alegre. 2004; (25):23-33.

8. Brasil. Decreto ${ }^{\circ} 9.771$, de 11 de abril de 2019. Aprova a Política Nacional de Drogas. Diário Oficial da União. 11 Abr 2019.

9. Brasil. Ministério da Saúde. Portaria n ${ }^{\circ} 3.088$, de 23 de dezembro de 2011. Institui a Rede de Atenção Psicossocial para pessoas com sofrimento ou transtorno mental e com necessidades decorrentes do uso de crack, álcool e outras drogas, no âmbito do Sistema Único de Saúde (SUS). Diário Oficial da União. 23 Dez 2011.

10. Araújo ND. Redução de Danos: história, práticas e desafios. In: Surjus LTLS, Silva PC, organizadores. Redução de danos: ampliação de vida e materialização de direitos. São Paulo: Unifesp; 2019.

11. Silva DC, Alvim NAT, Figueiredo PA. Tecnologias leves em saúde e sua relação com o cuidado em enfermagem hospitalar. Esc. Anna Nery Rev. Enferm. 2008; 12(2):291-298.

12. Simon AA. Sistematização de processos participativos: o caso de Santa Catarina. Rev. Brás. Agroecologia. 2007; 2(1):540-543.

13. Luczinsk GF, Ancona-Lopez M. A psicologia fenomenológica e a filosofia de Buber: o encontro na clínica. Estud. Psicol. 2010 [acesso em 2019 set 6]; 27(1):75-82. Disponível em: http://www.scielo.br/scie-
lo.php?pid=S0103-166X2010000100009\&script=sci abstract\&tlng=pt.

14. Sodelli MA. Abordagem proibicionista em desconstrução: compreensão fenomenológica do uso de drogas. Ciênc. Saúde Colet. 2010; 15(3):637-644.

15. Merleau-Ponty M. Fenomenologia da percepção. São Paulo: Martins Fontes; 1945

16. Ayres JRCM. Cuidado e reconstrução das práticas de saúde. Interface comun. saúde educ. 2004; 8(14):7392.

17. Bastos ADA, Alberti S. Crack! A redução de danos parou, ou foi a pulsão de morte? Psicol. USP. 2018; 29(2):212-225.

18. Anéas TV, Ayres JRCM. Significados e sentidos das práticas de saúde: a ontologia fundamental e a reconstrução do cuidado em saúde. Interface comun. saúde educ. 2011 [acesso em 2019 set 6]; 15(38):651662. Disponível em: http://www.scielo.br/scielo. php?pid=S1414- $2832011000300003 \&$ script $=$ sci $_{-}$ abstract\&tlng=pt

19. Rui T. "Isso não é um cachimbo": sobre usuários de crack, seus artefatos e suas relações. Áskesis. 2012; 1(1):32-45.

Recebido em 16/02/2019

Aprovado em 24/08/2019

Conflito de interesses: inexistente

Suporte financeiro: não houve 